\title{
Webquest x Webexercises: Uma Análise das Produções de Estagiários do Programa Institucional de Bolsas de Iniciação à Docência (PIBID) de Química Utilizando a Taxonomia Digital de Bloom
}

\section{Webquest $x$ Webexercises: an Analysis of Productions of the Institutional Scholarships Program of Teaching Initiation (PIBID) Trainees Using Bloom Digital Taxonomy}

David Pereira Faraum Junior ${ }^{1}$

Marcelo Maia Cirino²

'Universidade Estadual do Oeste do Paraná (UNIOESTE), Centro de Engenharias e Ciências Exatas, Toledo, PR, Brasil. Autor correspondente: david.junior1@unioeste.br

${ }^{2}$ Universidade Estadual de Londrina (UEL), Departamento de Química, Londrina, PR, Brasil.

Resumo: A WebQuest é uma atividade didática que utiliza qualquer artefato tecnológico com acesso à internet para a resolução de uma tarefa que suscite análise, síntese, avaliação e julgamento, que são habilidades cognitivas de ordem superior. Porém, estudos recentes mostram que a maioria dos autores falha exatamente neste componente, criando tarefas fáceis no formato de folhas de exercícios, denominadas de WebExercises. Esta pesquisa teve por objetivo analisar, utilizando a Taxonomia Digital de Bloom, as tarefas das WebQuests (WQs) criadas por dois grupos de estagiários do Programa Institucional de Bolsas de Iniciação à Docência (PIBID), do curso de Licenciatura em Química de uma universidade estadual do Estado do Paraná, para identificar os níveis de aprendizagem do domínio cognitivo atingidos por essas tarefas. Os resultados obtidos indicaram que as tarefas das WQs produzidas pelos pibidianos não alcançaram os níveis taxonômicos de habilidades de pensamento de ordem superior, portanto são classificadas como WebExercises.

Palavras-chave: WebQuest; WebExercises; Ensino de química; Taxonomia digital de Bloom; Formação inicial de professores.

\begin{abstract}
WebQuest is a didactic activity that uses any technological artifact with internet access to solve a task that requires analysis, synthesis, evaluation and judgment, which are higher order cognitive skills. However, recent studies show that most authors fail in exactly this component, because they create easy tasks in exercise sheet format, called WebExercises. The aim of this research was to analyze the tasks of the WebQuests created by two groups of Chemistry's students of the Institutional Program for Initiation to Teaching (PIBID) of a State university of Paraná, using the Bloom Digital Taxonomy as theoretical reference, to identification of the learning cognitive domain levels reached by these tasks. The results indicated that the WQ tasks produced by students did not reach the taxonomic levels of highest thinking ability, hence were classified as WebExercises
\end{abstract}

Keywords: WebQuest; WebExercises; Chemistry teaching; Bloom's digital taxonomy.; Initial teacher training.

Recebido em: $31 / 08 / 2018$

Aprovado em: 24/07/2019 


\section{Introdução}

O avanço das Tecnologias de Informação e Comunicação (TIC) no espaço escolar tem causado um grande impacto na educação, uma vez que sua utilização disponibiliza novas formas de abordagens para os processos de ensino e novas relações entre o educador e o educando. Esses recursos tecnológicos possibilitam ainda uma nova configuração didática, com aulas mais interativas e dinâmicas.

Desta forma, a discussão em torno da formação e a capacitação dos docentes para a utilização das tecnologias em sala de aula se tornou muito mais relevante. No processo de formação inicial do profissional da educação, a inserção da internet na escola deve ser extensivamente discutida, pois ela propicia a construção de novos meios de ensinar e aprender, a partir de novos veículos de diálogo e de trocas comunicativas, contribuindo assim para que o aprendiz assuma o protagonismo na construção do conhecimento e se constitua em um sujeito criativo em potencial.

Preocupado com a formação docente adequada para o uso de informações da internet, Bernie Dodge, professor da Universidade de San Diego (EUA), desenvolveu em 1995, durante um curso de capacitação de professores, a metodologia WebQuest (WQ) uma atividade orientada, em que algumas ou todas as informações que os estudantes irão interagir estão na Internet (DODGE, 1995).

Além disso, Abar e Barbosa (2008) afirmam que esta atividade didática, que apresenta como componentes: introdução, tarefa, processos e recursos, avaliação, conclusão e créditos, precisa ser elaborada de tal forma que os educandos possam se envolver na resolução de uma atividade investigativa.

Entre os componentes da WQ a tarefa é considerada a mais importante. Sua criação exige dos autores dedicação e criatividade, pois ela deve estar inserida no contexto da escola, ser desafiadora, motivante e, além disso, plausível, com respeito à sua resolução.

Entretanto, pesquisas de Bottentuit Junior e Coutinho (2011a, 2011b) indicam que a maioria dos autores erra exatamente nesta componente, pois criam tarefas fáceis ou extremamente complexas para serem resolvidas. Assim, é mais seguro seguir alguns preceitos do idealizador da WQ, os quais sugerem que as tarefas não sejam elaboradas como simples folhas de exercícios com resolução via computador, o que Dodge (1995) chama de WebExercises.

Partindo desse pressuposto, esta pesquisa teve por objetivo analisar, utilizando os níveis taxonômicos contidos na Taxonomia Digital de Bloom, as tarefas das WebQuests (WQs) produzidas por dois grupos de estagiários do Programa Institucional de Bolsas de Iniciação à Docência (PIBID), do curso de Química de uma universidade estadual do Paraná, para investigar se atingem (ou superam) os níveis de conhecimento das WebExercises.

\section{Referencial Teórico}

\section{A metodologia WebQuest}

A metodologia WebQuest foi proposta em 1995, pelo professor de Tecnologia Educacional, Bernie Dodge, da San Diego State University (SDSU), com a colaboração de seu aluno de graduação, Thomas March, durante um curso de capacitação de professores. 
Inicialmente, esse curso teria como objetivo apresentar aos professores-estudantes o funcionamento de uma simulação educacional a partir do software Arquetype ${ }^{1}$. Mas, devido à inquietação de Dodge sobre a utilização de atividades de busca de informações na Internet, para responder a perguntas simples, o caminho convencional foi alterado (BOTTENTUIT JUNIOR; SANTOS, 2014; SANTOS, 2011).

Deste modo, o professor da SDSU resolveu optar por uma estratégia de ensino que envolveu o trabalho colaborativo na busca de informações sobre o software, a partir de dados na Web previamente selecionados por ele, e que por si só ainda não pareciam suficientes. Dodge então propôs uma situação em que os professores-estudantes deveriam desempenhar a função de consultores, avaliando e recomendando, ou não, o software para um diretor de Escola (ABAR; BARBOSA, 2008; BOTTENTUIT JUNIOR; SANTOS, 2014).

Assim, a WQ surgiu da necessidade de se criar ambientes colaborativos para resoluções de problemas via Internet, que oferecessem atividades para estimular áreas cognitivas de níveis mais elevados, exigindo reflexão, análise, síntese e avaliação. Esta metodologia é definida por Dodge (1995, p. 1, tradução nossa) como "[...] uma investigação orientada, na qual algumas ou todas as informações com as quais os aprendizes interagem são originadas de recursos da Internet, opcionalmente suplementadas com videoconferências".

Para Bottentuit Junior e Santos (2014) as WQs são constituídas por seis componentes: introdução, tarefa, processo, avaliação, conclusão e créditos (Página do professor). Abar e Barbosa (2008) incluem os Recursos ao componente Processo, conforme a descrição a seguir.

- Introdução: um convite à descoberta incentivando e instigando o educando a realizar a tarefa. Este componente deve ser escrito de forma clara e objetiva, fornecendo algumas informações sobre o tema a ser abordado.

- Tarefa: estudiosos de WQs consideram este componente o mais importante. Por exemplo, Abar e Barbosa (2008) a consideram a "alma" ou o "coração" de uma WQ e desta forma exige-se reflexão por parte dos autores. Neste sentido, é necessário criar situações que busquem transformar as informações e por isso as mesmas não devem estar voltadas para conteúdos, mas sim para determinados processos cognitivos que se deseje alcançar.

- Processo e Recursos: o componente Processo traduz a dinâmica da atividade. Nele são expostas as informações a serem seguidas pelos estudantes. Logo, é de bom tom descrever detalhadamente as atividades a serem realizadas, podendo se atribuir diferentes papéis a cada educando do grupo. É importante esclarecer aos participantes que a cooperação entre o grupo vai garantir o sucesso da execução da tarefa. Junto a essa descrição é preciso inserir os recursos, que são os sites (sítios eletrônicos) onde o autor da WQ de antemão pesquisou, verificou a autenticidade e a relevância das informações para que os estudantes possam concretizar a tarefa proposta.

- Avaliação: neste componente devem-se expor,com clareza, os fatores que serãolevados em consideração na correção da tarefa. Na elaboração dos critérios quantitativos é importante considerar o nível cognitivo a ser alcançado pelo estudante no processo de resolução da mesma.

- Conclusão: enquanto a introdução é um convite para descobertas relacionadas à execução da tarefa, o componente Conclusão é um convite para aprender mais. Assim, este componente resume o propósito geral do que foi aprendido e indica como o estudante pode continuar a estudar o assunto.

1Programa utilizado para gerenciar e recuperar documentos, arquivos e informações de uma forma mais eficaz. 
- Créditos ou Página do professor: o componente Créditos, também chamado de 'página do professor', traz os dados do autor da WQ e indica a autoria dos recursos e das fontes disponibilizados, lembrando que, para Abar e Barbosa (2008), essas não são as referências indicadas para os estudantes no processo e recursos, mas sim o material utilizado para elaborar a WQ.

\title{
Um Olhar para a Tarefa
}

Desde a primeira publicação de Dodge, em 1995, a metodologia WQ vem ganhando espaço. Muitos professores multiplicaram suas ideias mundo afora, entretanto, as pesquisas de Bottentuit Junior e Coutinho (2008) e Santos (2011) evidenciaram a baixa qualidade das tarefas elaboradas em WQ em língua portuguesa. Até mesmo o próprio idealizador desta metodologia, ao realizar um levantamento próprio, concluiu que nem todos os desdobramentos da atividade pelo mundo foram satisfatórios, pois suas ideias foram distorcidas/alteradas, como ele mesmo esclarece:

\begin{abstract}
No início fiquei muito satisfeito que tanta gente tenha achado a ideia útil, mas depois verifiquei uma tendência perturbadora: o que a maior parte dos educadores das WebQuests estava criando não era o que eu tinha em mente na origem. Embora seguissem o formato de introdução, tarefa, processo, avaliação, eles focavam num baixo nível de recuperação de informação. Em vez de uma tarefa que suscitasse análise, síntese, avaliação, julgamento, solução de problema ou criatividade, $80 \%$ das novas WebQuests pediam respostas para simples questões para as quais havia apenas uma resposta certa. Isso, eu sabia, era uma preparação para o século XIX, não para o século XXI. (DODGE, 2006, p. 2 apud SANTOS, 2011, p. 110).
\end{abstract}

Para avaliar a usabilidade e a qualidade pedagógicas Bottentuit Junior e Coutinho (2008) analisaram 483 WQs em língua portuguesa, disponíveis online, entre julho e outubro de 2007 . Os resultados mostraram que apenas $41 \%$ delas foram consideradas verdadeiras WQs e, que mais da metade (59\%), não passavam de folhas de exercícios com respostas fechadas e pré-definidas com o formato de uma WQ às quais Dodge (1995) chama de WebExercises. São atividades que não exigem nenhuma reflexão e interatividade na elaboração de respostas e que apenas utilizam a interface da internet e a forma de uma WQ para reproduzir informações. Assim, portanto, se distanciam das ideias de Dodge, pois não possibilitam aos estudantes que produzam conhecimentos, pois as tarefas a serem resolvidas por eles seguem o modelo copiar e colar, que não contemplam os processos cognitivos de análise, síntese e avaliação (DODGE, 1995).

Portanto, as WebExercises não passam de páginas hospedadas na internet que possuem simples exercícios para as quais os estudantes se limitam a procurar informações na Web para, posteriormente, entregar as respostas. Em contrapartida, para ser considerada uma verdadeira WQ, a atividade precisa conter tarefas que solicitem a modificação da informação pesquisada transformando-a em um novo produto ou em uma nova informação, fruto das reflexões dos estudantes envolvidos.

Após esses apontamentos, podemos perceber que o papel do professor na elaboração de uma WQ é muito maior que propor uma simples busca de informações na internet, pois além de não proporcionar a construção efetiva de conhecimentos, a falta de planejamento, do início da pesquisa até a elaboração do produto final, pode desviar a atenção dos estudantes 
sobre o tema a ser abordado. A respeito desse cenário, Dodge (1995, p. 6, tradução nossa) afirma que:

Navegar na Internet pode ser um processo de busca de informações valioso na construção do conhecimento, gerando um rico ambiente interativo facilitador e motivador de aprendizagem, bem como pode ser um dispersivo e inútil coletar de dados sem relevância que não agregam qualidade pedagógica ao uso da rede.

Como autor de uma WQ, o professor deve planejar tarefas que encorajem os educandos a realizarem atividades que favoreçam a reflexão e, mais que isso, o professor deve monitorar e auxiliar as buscas dos estudantes durante os processos exigidos pela tarefa. Assim, uma das vantagens de se utilizar a WQ em situações de ensino é que os estudantes podem:

[...] transformar ativamente informações, em vez de apenas reproduzi-las: nos paradigmas tradicionais da educação, a preocupação central é com a transmissão e o armazenamento da 'matéria', já na perspectiva de uma WebQuest, o foco deve ser direcionado para a interação, compreensão e transformação das informações existentes, tendo em vista uma necessidade, um problema ou meta significativa. (ROCHA, 2007, p. 76).

Desta forma, a WQ pode auxiliar os estudantes no aprofundamento de conhecimentos e nas reflexões do seu próprio processo cognitivo, pois promove a construção colaborativa da aprendizagem. Mais ainda, seu uso também permite que os educandos atinjam resultados abertos e/ou inesperados a partir da resolução das tarefas propostas, mas para que isso aconteça é necessário aplicar a WQ nos níveis cognitivos de aprendizagem da Taxonomia de Bloom, buscando alcançar os níveis cognitivos mais elevados para se distanciar das WebExercises, conforme aponta a pesquisa de Rocha (2007), que estabelece uma relação entre a metodologia WQ e os níveis cognitivos da Taxonomia de Bloom, indicada na Figura 1.

Figura 1 - Relação entre a metodologia WebQuest e os domínios cognitivos da Taxonomia de Bloom

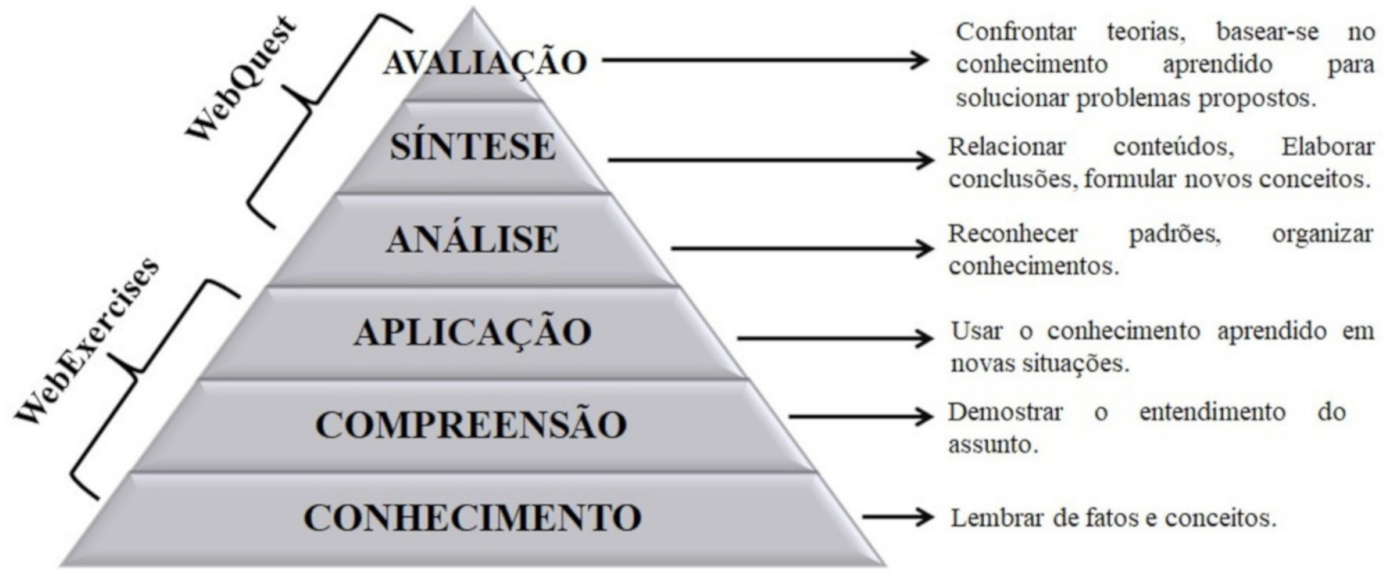

Fonte: Rocha (2007).

Observando atentamente a Figura 1, podemos constatar que para Rocha (2007) as WQs verdadeiras são aquelas que exploram os níveis de aprendizagem mais elevados: Análise, Síntese e Avaliação, mas como já foi ressaltado, a maioria das WQs produzidas não ultrapassam os dois primeiros níveis, sendo classificadas com WebExercises. 


\section{A Taxonomia de Bloom e suas Atualizações}

O sucesso da atividade WQ depende da definição de seus objetivos educacionais. Definindo esses objetivos, o educador pode prever os resultados a que se pretende chegar com a atividade e fornecer aos educandos os meios para que se organizem na resolução do problema. Rocha (2007) ressalta que a definição clara e precisa dos objetivos de uma WQ deve ser realizada a partir da Taxonomia dos Objetivos Educacionais, mais conhecida como Taxonomia de Bloom, que é uma proposta de classificação da aprendizagem dividida em seis níveis de domínio cognitivo.

A importância de utilizar o conceito de classificação para estruturar e organizar o processo educativo começou a ser discutida em 1948, pela Associação Norte Americana de Psicologia (American Psycological Association, APA), que solicitou a alguns de seus membros que criassem uma equipe de trabalho para discutir, definir e criar uma taxonomia dos objetivos de processos educacionais (LOMENA, 2006 apud FERRAZ; BELHOT, 2010, p. 422). Os educadores desenvolveram então, um sistema de classificação com três domínios: o afetivo que envolve as categorias ligadas ao desenvolvimento da área emocional e afetiva, que incluem comportamento, atitude, responsabilidade, respeito, emoção e valores, o psicomotor, relacionado com as habilidades físicas específicas divididas em seis categorias que incluem ideias ligadas a reflexos, percepção, habilidades físicas, movimentos aperfeiçoados e comunicação não verbal, e o cognitivo que é o mais utilizado pelos educadores na elaboração dos planejamentos educacionais, dos objetivos, estratégias e sistemas de avaliação (FERRAZ; BELHOT, 2010).

Os objetivos educacionais do domínio cognitivo "[...] incluem aqueles vinculados à memória ou recognição e ao desenvolvimento de capacidades e habilidades intelectuais" (BLOOM et al., 1974, p. 6). Assim, este domínio "[...] envolve a aquisição de um novo conhecimento, do desenvolvimento intelectual, de habilidades e de atitudes. Inclui reconhecimento de fatos específicos, procedimentos padrões e conceitos que estimulam o desenvolvimento intelectual constantemente" (FERRAZ; BELHOT, 2010, p. 422).

Bloom et al. (1974, p. 10) esclarecem alguns pontos importantes acerca do processo de classificação dos objetivos didáticos:

[...] os principais fenômenos de nosso interesse são as mudanças que ocorrem nos indivíduos, resultantes de experiências educacionais. Estas mudanças podem ser representadas pelas exposições globais dos objetivos de uma unidade educacional ou pela descrição real dos comportamentos do aluno que são considerados adequados e relevantes para os objetivos.

Acrescentam, além disso, que:

[...] não pretendemos classificar metodologias de ensino, modos de relacionamento de professores com alunos ou diferentes tipos de materiais de ensino empregados. Estamos classificando o comportamento esperado - modos em que os alunos devem agir, pensar ou sentir como resultado de sua participação em alguma unidade de ensino (BLOOM et al., 1974, p. 11). 
As competências do Domínio Cognitivo são engendradas em níveis de complexidade crescente, isso significa que para adquirir uma nova habilidade pertencente ao próximo nível, o educando deve ter dominado e adquirido a habilidade do nível inferior. Só depois de conhecer um determinado assunto/conceito é que se pode compreendê-lo e aplicá-lo (FERRAZ; BELHOT, 2010).

Assim, a taxonomia proposta não é apenas um esquema de classificação, mas uma possibilidade de organização hierárquica dos processos cognitivos de acordo com níveis de complexidade e objetivos do desenvolvimento cognitivo desejado e planejado (FERRAZ; BELHOT, 2010). Portanto, os níveis da taxonomia de Bloom representam os resultados de aprendizagem esperados e como são acumulativos, caracterizam-se pela relação de dependência entre si e são organizados em termos de complexidades dos processos mentais.

Bloom et al. (1974) descreveram cada nível do domínio cognitivo, sendo que o nível do conhecimento consiste na habilidade de lembrar informações sobre fatos, datas, teorias, métodos, classificações, regras, critérios e procedimentos; o nível da compreensão corresponde ao entendimento de informações e a sua utilização em contextos diferentes; o nível da aplicação é a habilidade de aplicar conhecimento em situações concretas; já no nível da análise, o indivíduo é capaz identificar as partes e suas inter-relações; o nível da síntese se caracteriza a combinação das partes não organizadas para formar um todo; e o último nível a avaliação, que tem como característica julgar o valor do conhecimento.

Com o passar dos anos surgiram novos conceitos, recursos e teorias que foram incorporados ao campo educacional. Os avanços pedagógicos e tecnológicos fizeram a Associação de Psicologia Americana convidar novamente membros da associação para realizarem uma revisão e atualização da Taxonomia de Bloom apresentada em 1956. Foi então que Anderson e Krathwohl (2001) editaram o livro A taxonomy for learning, teaching and assessing: a revision of Bloom's taxonomy for educational objectives. As mudanças realizadas na taxonomia de Bloom podem ser observadas na Figura 2, a seguir.

Figura 2 - Taxonomia Revisada de Bloom realizada por Anderson e Krathwohl (2001)

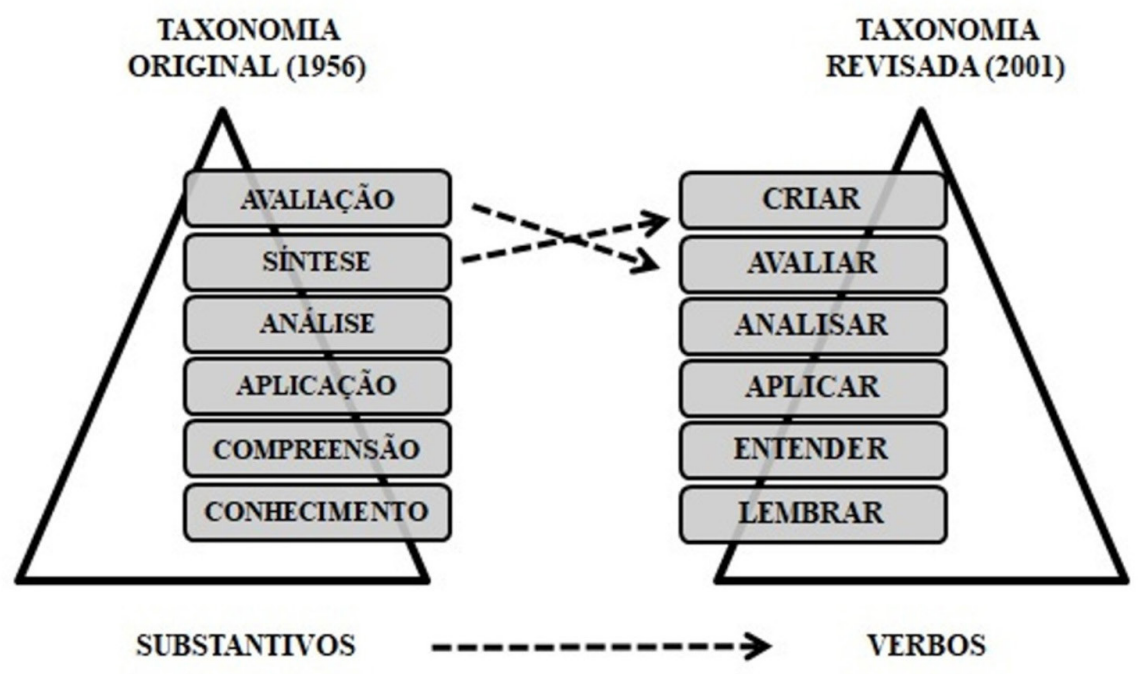

Fonte: adaptado de Churches (2009) e Paiva (2011). 
Essa revisão foi necessária, pois durante os 45 anos da utilização da taxonomia de Bloom ocorreram mudanças significativas na forma de se conceber os processos de ensino e de aprendizagem. Um dos aspectos importantes desta revisão foi a substituição dos substantivos por verbos para descrever cada categoria. Isso ocorreu devido à concepção defendida por Anderson e Krathwohl (2001 apud CHURCHES, 2009) de que no processo de aprendizagem o educando é o agente ativo, ou seja, ele busca construir seu próprio conhecimento.

A mudança substancial com relação à primeira taxonomia diz respeito à visão de que "[...] o aluno constrói o próprio significado de sua aprendizagem com base em conhecimentos prévios, em atividades cognitivas e metacognitivas e em oportunidades e limitações disponíveis no contexto educacional" (ANDERSON; KRATHWOHL, 2001, apud MARTINS, 2013, p. 63).

Desta forma, algumas categorias foram renomeadas como: conhecimento por lembrar; compreensão por entender e síntese por criar. E as categorias aplicação, análise e avaliação, foram alteradas respectivamente para os verbos: aplicar, analisar e avaliar. Para os criadores da taxonomia revisada esta mudança era necessária para expressar melhor a ação pretendida, com o objetivo e os resultados que se esperam para determinados estímulos de instrução (PAIVA, 2011).

Além disso, a nova taxonomia, apesar de apresentar uma estrutura hierarquizada, é flexível, "[...] devido ao fato de que determinados conteúdos podem ser mais fáceis de serem assimilados a partir do estímulo pertencente a uma mais complexa. Por exemplo, pode ser mais fácil entender um assunto após aplicá-lo e só então ser capaz de explicá-lo" (FERRAZ; BELHOT, 2010, p. 427).

Outra modificação ocorreu com as categorias avaliação e síntese (agora avaliar e criar), que foram trocadas de lugar dentro do domínio cognitivo, isso porque Anderson e Krathwohl consideram que a criação alcança um nível maior dentro do domínio cognitivo do que a avaliação. (CHURCHES, 2009).

\section{A Taxonomia Digital de Bloom}

A atualização mais recente da Taxonomia de Bloom foi realizada em 2009, pelo neozelandês Andrew Churches, e publicada no site Eduteka, sob o título Bloom's digital taxonomy (CHURCHES, 2009). Esta taxonomia busca atender aos novos comportamentos e oportunidades de aprendizagem, com a incorporação das Tecnologias de Informação e Comunicação (TIC) em sala de aula, uma vez que Anderson e Krathwohl (2001 apud CHURCHES, 2009), da Taxonomia Revisada de Bloom, não consideram as novas tecnologias, nem os processos e ações que lhes são associados, e que estão tão presentes na vida dos nativos digitais, que segundo Palfrey e Gasser (2011) são aqueles nascidos depois de 1980 e com habilidades quanto ao uso das tecnologias.

Desta forma, Churches (2009) relaciona o domínio cognitivo previsto descritos na taxonomia revisada por Anderson e Krathwohl (2001 apud CHURCHES, 2009, p. 1) lembrar, entender, aplicar, analisar, avaliar e criar - com os recursos didático-tecnológicos oferecidos pela segunda geração da internet, a Web 2.0 ${ }^{1}$, e concentra-se na qualidade da ação ou do processo que definem o nível cognitivo. Portanto, Churches (2009) associa os

\footnotetext{
${ }^{1} \mathrm{~A}$ Web 2.0 é a segunda geração dos serviços online responsável pela ampliação dos espaços de interação entre os usuários da internet.
} 
comportamentos esperados dos estudantes e as ações digitais realizadas a partir do uso de ferramentas tecnológicas para alcançar cada nível taxonômico.

Por exemplo, o nível lembrar está "[...] relacionado a reconhecer e reproduzir ideias e conteúdos. Reconhecer requer distinguir e selecionar uma determinada informação e reproduzir ou recordar está mais relacionado à busca por uma informação relevante memorizada" (FERRAZ; BELHOT, 2010, p. 429), e entre as ações digitais que Churches (2009) elenca deste nível podemos destacar:

- Marcar favoritos - neste processo os alunos podem marcar e organizar sites, recursos e arquivos para usar futuramente.

- Participar de redes sociais - É o lugar onde as pessoas desenvolvem redes de amigos e associados; criam ligações entre diferentes pessoas. Como marcadores sociais, uma rede social pode tornar-se um elemento chave de colaboração.

- Pesquisar, googlar - Atualmente, os motores de busca são amplamente usados pelos estudantes, devido à facilidade em utilizar os buscadores. Neste nível a pesquisa é simples, não indo além busca pela palavra-chave ou do termo a ser pesquisado.

Assim, este nível taxonômico está ligado à recuperação da informação, já que é impossível, tanto para o professor quanto para o educando, lembrar e manter todos os conhecimentos atuais relevantes para a sua aprendizagem (CHURCHES, 2009).

A seguir, no Quadro 1, estão detalhados os níveis cognitivos de aprendizagem segundo a Taxonomia de Bloom Revisada (ANDERSON; KRATHWOHL, 2001 apud FERRAZ; BELHOT 2010) e a Taxonomia Digital de Bloom (CHURCHES, 2009).

Quadro 1 - Descrição dos níveis de aprendizagem segundo a Taxonomia de Bloom Revisada e a Taxonomia Digital de Bloom

\begin{tabular}{|c|c|c|c|}
\hline $\begin{array}{l}\text { Categorias / Níveis } \\
\text { taxonômicos }\end{array}$ & Definição & Verbos & $\begin{array}{l}\text { Ações digitais propostas por } \\
\text { Churches (2009) }\end{array}$ \\
\hline Lembrar & $\begin{array}{l}\text { Lembrar requer distinguir e selecionar } \\
\text { uma determinada informação e repro- } \\
\text { duzir ou recordar está mais relacionado } \\
\text { à busca por uma informação relevante } \\
\text { memorizada. }\end{array}$ & $\begin{array}{l}\text { Definir, descrever, identificar, saber, } \\
\text { etiquetar, listar, corresponder, nomear, } \\
\text { delinear, lembrar, reconhecer, reprodu- } \\
\text { zir, selecionar, afirmar. }\end{array}$ & $\begin{array}{l}\text { Marcar favoritos, participar de re- } \\
\text { des sociais, realizar buscas "goo- } \\
\text { glar", enviar mensagens de texto. }\end{array}$ \\
\hline Entender & $\begin{array}{l}\text { Estabelecer uma conexão entre o novo } \\
\text { e o conhecimento previamente adquiri- } \\
\text { do. A informação é entendida quando o } \\
\text { aprendiz consegue reproduzi-la com suas } \\
\text { "próprias palavras". }\end{array}$ & $\begin{array}{l}\text { Compreender, converter, defender, dis- } \\
\text { tinguir, classificar, explicar, estender, } \\
\text { generalizar, dar um exemplo, inferir, } \\
\text { interpretar, parafrasear, predizer, rees- } \\
\text { crever, sumarizar, traduzir. }\end{array}$ & $\begin{array}{l}\text { Realizar pesquisas Avançadas, } \\
\text { postar em um Blog, classificar } \\
\text { categorias e Tags, participar de } \\
\text { chat, comunicar-se via e-mail. }\end{array}$ \\
\hline Aplicar & $\begin{array}{l}\text { Executar ou usar um procedimento numa } \\
\text { situação específica e pode também abor- } \\
\text { dar a aplicação de um conhecimento } \\
\text { numa situação nova. }\end{array}$ & $\begin{array}{l}\text { Aplicar,demonstrar, executar, manipu- } \\
\text { lar, modificar, operar, prever, preparar, } \\
\text { produzir, mostrar, resolver, usar. }\end{array}$ & $\begin{array}{l}\text { Executar e operar hardware e } \\
\text { aplicativos de computador, jo- } \\
\text { gar, enviar e compartilhar. }\end{array}$ \\
\hline Analisar & $\begin{array}{l}\text { Relacionado a dividir a informação em } \\
\text { partes relevantes e irrelevantes, impor- } \\
\text { tantes e menos importantes e entender } \\
\text { a inter-relação existente entre as partes. }\end{array}$ & $\begin{array}{l}\text { Analisar, decompor, comparar, contras- } \\
\text { tar, desconstruir, diferenciar, discrimi- } \\
\text { nar, distinguir, identificar, ilustrar, infe- } \\
\text { rir, esboçar, referir, selecionar, separar. }\end{array}$ & $\begin{array}{l}\text { Recombinar, fazer ligações, reu- } \\
\text { nir-se em rede, realizar videocon- } \\
\text { ferência. }\end{array}$ \\
\hline Avaliar & $\begin{array}{l}\text { Realizar julgamentos baseados em crité- } \\
\text { rios e padrões qualitativos e quantitativos } \\
\text { ou de eficiência e eficácia. Na Taxonomia } \\
\text { original era a categoria de nível mais ele- } \\
\text { vado, na revisada fica na quinta posição. }\end{array}$ & $\begin{array}{l}\text { Avaliar, comparar, concluir, contrastar, } \\
\text { criticar, criticar, defender, descrever, } \\
\text { discriminar, avaliar, explicar, interpretar, } \\
\text { justificar, resumir, apoiar. }\end{array}$ & $\begin{array}{l}\text { Postar e refletir comentários em } \\
\text { Blog e vlog, publicar, colaborar e } \\
\text { trabalhar na rede, debater. }\end{array}$ \\
\hline Criar & $\begin{array}{l}\text { Significa colocar elementos junto com } \\
\text { o objetivo de criar uma nova visão, uma } \\
\text { nova solução, estrutura ou modelo utili- } \\
\text { zando conhecimentos e habilidades pre- } \\
\text { viamente adquiridos. Envolve o desen- } \\
\text { volvimento de ideias novas e originais, } \\
\text { produtos e métodos por meio da percep- } \\
\text { ção da interdisciplinaridade e da interde- } \\
\text { pendência de conceitos. }\end{array}$ & $\begin{array}{l}\text { Categorizar, combinar, compilar, com- } \\
\text { por, criar, inventar, projetar, explicar, } \\
\text { gerar, modificar, organizar planos, reor- } \\
\text { ganizar, reconstruir, reorganizar, rever, } \\
\text { reescrever, resumir, dizer, escrever }\end{array}$ & $\begin{array}{l}\text { Programar, filmar, animar, blogar, } \\
\text { vídeo- blogar, mesclar, participar } \\
\text { em wiki (wiking), publicar, video- } \\
\text { casting, podcasting, }\end{array}$ \\
\hline
\end{tabular}

Fonte: adaptado de Churches (2009) e Ferraz e Belhot (2010). 
Churches (2009), autor da Taxonomia Digital de Bloom, esclarece que o foco não é sobre as ferramentas tecnológicas, mas sim sobre como são utilizadas nos processos de ensino e de aprendizagem, pois para ele as ferramentas não são o fim em si, mas os meios para atingir os níveis cognitivos. Deste modo, um determinado recurso pode ser encontrado em mais de um nível taxonômico, como o You Tube ${ }^{1}$ utilizado tanto para lembrar quanto para criar um conteúdo.

Ainda sobre a Taxonomia para a era digital, Churches (2009) afirma que, apesar da categorização dos níveis possuir uma hierarquia, o processo de aprendizagem pode se iniciar em qualquer momento. Alinhado a isto, Paiva e Padilha $(2012$, p. 87) acreditam que no contexto online a hierarquização não faz sentido, pois "[...] os níveis cognitivos podem transitar continuamente, com certo grau de fluidez, sem, no entanto, perder a peculiaridade e a predominância de cada nível".

Pensando na utilização da metodologia WQ no ensino de Química, acreditamos que a Taxonomia Digital de Bloom possa auxiliar o educador no processo de elaboração de atividades, que ao serem resolvidas, atinjam níveis cognitivos elevados, atendendo assim às orientações do criador da WQ.

\section{Metodologia}

A pesquisa, de natureza qualitativa, foi desenvolvida com estagiários do Programa Institucional de Bolsas de Iniciação à Docência (PIBID) de Química de uma universidade estadual do Paraná, em 2016. Os pibidianos foram divididos em dois grupos (WebQuest, grupo 1 e WebQuest, grupo 2) seguindo a orientação do coordenador do PIBID de Química e obedecendo a divisão entre os professores supervisores das Escolas em que os pibidianos desenvolviam suas atividades de estágio. No total participaram 8 estagiários (cinco participantes do grupo 1 e três participantes do grupo 2).

O processo de organização e estruturação dos dados foi realizado por meio da Análise Textual Discursiva (ATD), que é um processo de autoconhecimento, em que, num primeiro momento tem interesse em descrever/entender o fenômeno, a partir de quatro etapas:

1. Desmontagem dos textos: também denominado de processo de unitarização, implica examinar os textos fragmentando-os no sentido de atingir as unidades de análise;

2. Estabelecimento de relações: este processo é denominado de categorização envolve construir relações entre as unidades de base;

3. Captação do novo emergente: o metatexto resultante desse processo representa um esforço de explicitar a compreensão que se apresenta como produto de uma nova combinação dos elementos construídos ao longo dos passos anteriores;

4. Auto organização do processo: o ciclo de análise em seu todo pode ser compreendido como um processo auto organizado do qual emergem novas compreensões (MORAES; GALIAZZI, 2007).

A matéria prima da ATD é o corpus da pesquisa e que, segundo Moraes e Galiazzi (2007, p. 16), "[...] se constitui essencialmente de produções textuais, a partir das quais são construídos significados relativos aos fenômenos investigados".

\footnotetext{
'Site da internet que permite que seus usuários carreguem e compartilhem vídeos em formato digital.
} 
No caso desta pesquisa, para análise das tarefas das WQs, produzidas pelos estagiários, foram utilizados os 'enunciados' das mesmas. Neste processo de compreender como as tarefas das WQs poderiam contribuir para alcançar os níveis de conhecimento descritos na Taxonomia Digital de Bloom, o processo de categorização foi realizado por meio do método dedutivo, "[...] um movimento do geral para o particular, que implica em construir categorias antes mesmo de examinar o 'corpus'". (MORAES; GALIAZZI, 2007, p. 23).

Estas categorias, criadas a priori no caso desta investigação, foram os níveis de aprendizagem do domínio cognitivo da Taxonomia Digital de Bloom: Lembrar, Entender, Aplicar, Analisar, Avaliar e Criar, conforme indicado no Quadro 1.

\section{Resultados e Conclusão}

\section{Análise da tarefa do Grupo 1}

O tema das WQs produzidas pelos grupos foi o mesmo, os Óxidos, mas com problemáticas diferentes. O grupo 1 utilizou o fenômeno da chuva ácida ${ }^{1}$ para tratar do tema, sendo que os componentes tarefa e processos produzidos pelos pibidianos estão indicados no Quadro 2.

Quadro 2 - Tarefa da webquest do grupo 1

\begin{tabular}{|l|l|}
\hline Componente da WebQuest & \multicolumn{1}{|c|}{ Enunciado/Descrição } \\
\hline Tarefa & $\begin{array}{l}\text { Utilizando cartazes feitos em sala de aula em equipes de até 5 estudantes, os alunos } \\
\text { deverão fazer uma breve apresentação informal tratando do tema chuva ácida, apre- } \\
\text { sentando informações de grande relevância sobre o assunto, como as causas, conse- } \\
\text { quências e as formas de evitar esse fenômeno. }\end{array}$ \\
\hline Processos & $\begin{array}{l}\text { (1) O que é chuva ácida? Explique com suas palavras; } \\
\text { (2) Como há a formação da chuva ácida? Mostre as reações que ocorrem no processo; } \\
\text { (3) A que função inorgânica pertencem as substâncias envolvidas na formação da chu- } \\
\text { va ácida?; } \\
\text { (4) A chuva já é naturalmente ácida. Explique essa afirmação; } \\
\text { (5) Quando consideramos que uma chuva é ácida e qual seu efeito sobre o meio am- } \\
\text { biente e construções? }\end{array}$ \\
\hline
\end{tabular}

Fonte: elaborado pelos autores a partir da webquest produzida pelos estagiários do PIBID do grupo 1.

A tarefa resume-se à elaboração de cartazes contendo informações que respondam às questões referentes à origem, causas e efeitos da chuva ácida, bem como às funções inorgânicas a qual esse fenômeno se relaciona. Dodge (2002 apud PAIVA; PADILHA, 2012, p. 95) alerta que tarefas deste tipo, sem uma situação-problema pode ocasionar a desmotivação e o desinteresse dos estudantes em realizar a WQ.

A partir da resolução da tarefa elaborada pelo grupo 1 espera-se que o estudante seja capaz de compreender a informação recolhida e consiga reproduzi-la com suas próprias palavras, na confecção dos cartazes, ou seja, um comportamento esperado do domínio cognitivo entender, que segundo Ferraz e Belhot (2010) significa estabelecer uma conexão entre o novo conhecimento e o conhecimento previamente adquirido, em que a informação entendida pode ser reproduzida com as próprias palavras do estudante.

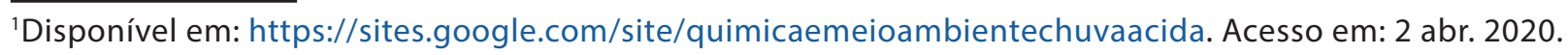


A ação digital exigida para resolução da atividade se resume a realizar buscas de informações nos sites disponibilizados na WQ. Assim, segundo a Taxonomia Digital de Bloom, a tarefa não supera o nível taxionômico lembrar que está relacionado à recuperação de informações a partir de buscas simples na web.

Analisando os enunciados das questões da WQ da chuva ácida, podemos observar o processo de:

a. reconhecer - A que função inorgânica pertencem as substâncias;

b. explicar - Explique com suas palavras. Explique essa afirmação;

c. mostrar - Mostre as reações que ocorrem no processo.

Segundo a Taxonomia Revisada de Bloom, estas ações estão presentes nos níveis taxonômicos lembrar, entender e aplicar respectivamente, conforme indica o Quadro 1.

Deste modo, o educando, ao resolver a tarefa proposta pela WQ do grupo 1, poderá alcançar até o terceiro nível de apredizagem, desenvolvendo o que Churches (2009) chama de habilidades de pensamento de ordem inferior, ou seja, a atividade não pode ser considerada uma webQuest, mas sim uma webExercise.

\section{Análise da tarefa do Grupo 2}

A webquest ${ }^{1}$ do grupo 2 teve como temática o uso dos óxidos na agricultura, apresentando a tarefa e o processo descritos no Quadro 3.

Quadro 3 - Tarefa da webquest do grupo 2

\begin{tabular}{|c|c|}
\hline $\begin{array}{c}\text { Componente da } \\
\text { WebQuest }\end{array}$ & Enunciado/Descrição \\
\hline Tarefa & $\begin{array}{l}\text { Fernando é um agricultor de girassol iniciante, ou seja, ele ainda não entende muito onde pode } \\
\text { plantar sem ter problemas na planta, porém você como aluno de química muito aplicado tem ideia } \\
\text { de como pode ajudá-lo nesta tarefa. } \\
\text { Com uma pequena pesquisa no Google descobre que um solo ácido não é bom para o plantio do } \\
\text { mesmo. Com alguns amigos e ajuda de equipamentos adequados vocês analisam o solo e desco- } \\
\text { brem que ele está ácido com valor de } 4,8 \text { e sabem que para plantação do girassol é necessário que } \\
\text { o solo esteja com o pH acima de } 5,2 \text {. E agora, o que fazer? } \\
\text { Você necessita de algo que aumente o pH do solo (já que o solo ácido possui um pH baixo). É ne- } \\
\text { cessária então a adição de CaO (cal virgem) ao solo e esse processo é chamado de calagem, onde o } \\
\mathrm{CaO} \text { óxido de cálcio, reage com a água para formar } \mathrm{Ca}(\mathrm{OH}) 2 \text {, que irá reagir com os íns H+(ácido) } \\
\text { e formar íons Ca2+e, novamente, } \mathrm{H} 2 \mathrm{O} \text {. } \\
\text { Até aí tudo bem, porém Fernando é um agricultor consciente e bem curioso e quer informação. } \\
\text { Qual reação você escreveria para que ele entendesse o processo, sabendo que o CaO reage com a } \\
\text { água? Como um óxido é formado? Como são classificados os óxidos? E quais são os principais } \\
\text { óxidos que encontramos no dia-a-dia? } \\
\text { Assim você ajudará Fernando a ter uma ideia de como funciona o pH de um solo e entenderá um } \\
\text { pouco mais sobre isso. }\end{array}$ \\
\hline Processos & $\begin{array}{l}\text { Entender as reações que ocorrem entre óxidos e água; } \\
\text { Entender a formação de óxidos; } \\
\text { Saber utilizar a nomenclatura de óxidos; } \\
\text { Chegar a um consenso nas respostas da Tarefa; } \\
\text { Saber a diferença entre óxido ácido e básico; } \\
\text { O grupo deverá fazer o trabalho em slides para apresentação (no formato seminário), que de- } \\
\text { verá conter as seguintes informações: } \\
\text { (1) Responder as questões oralmente como se fosse para o agricultor Fernando, exemplificando } \\
\text { para o melhor entendimento do mesmo; } \\
\text { (2) Fazer a reação dos óxidos usados nos exemplos do cotidiano, com água e mostrar onde são } \\
\text { usados; } \\
\text { (3) Discussão final sobre as dificuldades encontradas na realização da pesquisa e realização do } \\
\text { trabalho. }\end{array}$ \\
\hline
\end{tabular}

Fonte: elaborado pelos autores a partir da webquest produzida pelos estagiários do PIBID do grupo 2 . 
A Tarefa da WQ do grupo 2 propõe uma situação-problema envolvendo o plantio de girassol e a utilização do Óxido de Cálcio $(\mathrm{CaO})$, no processo conhecido como calagem. Coelho e Vidal (2009, p. 1-2) ressaltam que "[...] o modelo WebQuest se caracteriza pela integração da tecnologia ao currículo escolar a partir de uma metodologia problematizadora, posto utilizar situações de ensino-aprendizagem reais em contextos voltados para a investigação." Desta forma, estimula o estudante a resolver a atividade.

Os verbos usados e subentendidos na tarefa da WQ foram:

a. nomear - saber utilizar a nomenclatura de óxidos;

b. listar - quais são os principais óxidos que encontramos no dia-a-dia?;

c. entender - as reações que ocorrem entre óxidos e água, a formação de óxidos;

d. mostrar - e mostrar onde são usados; e,

e. diferenciar - saber a diferença entre óxido e óxido ácido.

Os verbos explorados encontram-se, respectivamente, nos níveis da Taxonomia Revisada de Bloom lembrar, entender, aplicar e analisar, como estabelecido no Quadro 1.

Entre as ações digitais a serem executadas ao longo da resolução da situaçãoproblema da WQ do grupo 2 podemos destacar a busca por informações disponibilizadas no componente recursos e a elaboração de uma apresentação em Power Point para ser apresentada em forma de seminário. Churches (2009) comenta que, fazer o uso de ferramentas digitais como apresentadores multimídias para mostrar os resultados de alguma tarefa, são meios para se atingir o nível cognitivo aplicar.

Desta forma, acreditamos que a resolução da tarefa desta WQ pode atingir o nível taxonômico aplicar porque, segundo Ferraz e Belhot (2010), esta habilidade de pensamento está relacionada ao uso de um procedimento aprendido em uma situação já conhecida ou nova, na qual, para resolver a situação proposta sobre a plantação de girassóis, o estudante precisa articular os conceitos relacionados ao uso da função óxidos com a manutenção do $\mathrm{pH}$ do solo.

Vale ressaltar ainda que a discussão e o compartilhamento de informações referentes às dificuldades e aos resultados da tarefa, conforme indicado no componente processo da WQ, podem ser meios para se alcançar níveis cognitivos mais elevados, como por exemplo, analisar. Churches (2009) elenca como ação deste nível, a 'colaboração' e a participação em redes, embora no caso específico desta WQ não seja exatamente isso, mas a participação dos estudantes na discussão e na busca pelo consenso sobre as respostas/resoluções da atividade.

Portanto, consideramos que a tarefa elaborada pelo grupo 2 pode alcançar o nível taxionômico aplicar, classificando a atividade como WebExercise, tanto em relação ao comportamento esperado pelo estudantes de utililizar o conhecimento em uma situação específica, quanto pela ação digital de utilizar apresentadores multimídias (Power Point ${ }^{\circledR}$ ) para desenvolver e apresentar os resultados das tarefas solicitadas.

\section{Considerações Finais}

Por meio da Taxonomia Digital de Bloom foi possível constatar que os níveis cognitivos dos verbos explorados na tarefa do grupo 1 encontram-se nos níveis taxonômicos mais simples: lembrar, entender e aplicar. Entre as ações digitais que Churches (2009) elenca na sua taxonomia, encontramos apenas a ação referente à busca por informações nos sites disponibilizados no componente recursos. Desta maneira, entendemos que existe a necessidade de se ampliar o uso de recursos oferecidos pela Web 2.0. 
Com relação à tarefa elaborada pelo grupo 2, podemos perceber que os níveis taxonômicos alcançados pelos verbos utilizados nos enunciados são os mesmos, ou seja, classificam a atividade de pesquisa como WebExercises, mas com a ressalva de que a exposição de uma situação real e sua problematização se constituem nos fundamentos básicos do modelo WQ, que por sua vez assenta-se numa postura predominantemente problematizadora. (COELHO; VIDAL, 2009).

Uma das ações digitais exigidas para a resolução da tarefa do grupo 2 foi a elaboração de uma apresentação, na forma de seminário, desenvolvida a partir do aplicativo multimídia Power Point ${ }^{\circledR}$, que para Churches (2009), se encontra no nível cognitivo aplicar, em que o educando pode compartilhar com a turma a resolução da situação-problema (ação que o autor considera muito importante, como habilidade para o século XXI). O ato de cooperar possibilita ainda que os estudantes possam atingir níveis elevados de aprendizagem, já que podem analisar e avaliar as informações compartilhadas e futuramente criar um produto novo.

Neste sentido, consideramos que os pibidianos poderiam explorar mais as mídias da Web 2.0 como, por exemplo, o compartilhamento de ideias por meio das redes sociais, fóruns de discussões em comunidades ou aplicativos de troca de mensagens e bloggar, que se enquadram nos níveis mais complexos da Taxonomia Digital de Bloom e exigem mais criticidade e interatividade entre os estudantes.

Depreende-se que a proposta de um trabalho colaborativo, utilizando as novas tecnologias, não é tarefa fácil, porque o professor necessita de formação apropriada e não somente de cursos preparatórios com carga horária reduzida. É preciso também que ocorra a integração entre o uso das tecnologias e o ensino de Química, no sentido de superar as práticas tradicionais de transmissão de conhecimento.

Nos dias de hoje, em que se busca a construção de uma nova configuração educacional, integrada aos atuais espaços de construção do conhecimento, acreditamos que os pibidianos precisam conhecer melhor a metodologia proposta por Dodge (1995) e a Taxonomia Digital de Bloom (CHURCHES, 2009). Apesar de recente, podem auxiliar na elaboração de uma webQuest que proporcione aos educandos competências e habilidades cognitivas de ordem superior.

\section{Agradecimentos}

Agradecemos à Coordenação de Aperfeiçoamento de Pessoal de Nível Superior (CAPES) pelo apoio financeiro por meio da bolsa de estudo em nível de mestrado, oportunizando a realização desta pesquisa.

\section{Referências}

ABAR, C. A. A. P.; BARBOSA, L. M. Webquest: um desafio para o professor! uma solução inteligente para o uso da internet. São Paulo: Avercamp, 2008.

ANDERSON, L.W; KRATHWOHL, D. R. (ed.). A taxonomy for learning, teaching and assessing: a revision of Bloom's taxonomy of educational objectives. New York: Longman, 2001.

BLOOM, B. S.; ENGELHART, M. D.; FURST, E. J.; HILL, W. H.; KRATHWOHL, D. R. Taxonomia de objetivos educacionais. Porto Alegre: Editora Globo, 1974. v. 1. 
BOTTENTUIT JUNIOR, J. B.; COUTINHO, C. P. Análise das componentes e a usabilidade das webquests em língua portuguesa disponíveis na web: um estudo exploratório. JISTEM: journal of information systems and technology management, São Paulo, v. 5, n. 3, p. 453-468, 2008.

BOTTENTUIT JUNIOR, J. B.; COUTINHO, C. P. Recomendações de qualidade para o processo de avaliação de webquests. EduSer: revista de educação, Bragança, v. 3, n. 2, p. 45-59, 2011 a.

BOTTENTUIT JUNIOR, J. B.; COUTINHO, C. P. Indicadores de qualidade para a avaliação de WebQuest: algumas recomendações. In: ENCONTRO NACIONAL DE HIPERTEXTO E TECNOLOGIAS EDUCACIONAIS, 4., 2011, Sorocaba. Anais [...]. Sorocaba: Universidade de Sorocaba, 2011b. p. 1-14.

BOTTENTUIT JUNIOR, J. B.; SANTOS, C. G. Revisão sistemática da literatura de dissertações sobre a metodologia webquest. Revista EducaOnline, Rio de Janeiro, v. 8, n. 2, p. 1-41, 2014.

CHURCHES, A. Bloom's digital taxonomy. 2009. Disponível em: https://www.academia.edu/30868755/ Andrew_Churches_-_Blooms_Digital_Taxonomy.pdf. Acesso em: 5 out. 2016.

COELHO, L. C. A.; VIDAL, E. M. Análise de webquests: contribuições da metodologia da problematização. Revista Tecnologias na Educação, v. 1, n. 1, p. 1-8, dez. 2009.

DODGE, B. Webquests: a technique for internet-based learning. The Distance Educator, London, v. 1, n. 2, p. 10-13, 1995.

FERRAZ, A. P. C. M.; BELHOT, R. V. Taxonomia de Bloom: revisão teórica e apresentação das adequações do instrumento para definição de objetivos instrucionais. Gestão \& Produção, São Carlos, v. 17, n. 02, p. 421-431, 2010. DOI: https://doi.org/10.1590/S0104-530X2010000200015

KRATHWOL, D. R. Revision of Bloom's taxonomy: an overview. Theory into Practice, Columbus, v. 41, n. 4, p. 212-218, 2002.

LEITE, B. S. Tecnologias no ensino de química: teoria e prática na formação docente. Curitiba: Appris, 2015.

MARTINS, M. A. B. Avaliação da aprendizagem em cursos de pós-graduação lato sensu em administração na EAD online: um estudo em uma instituição de ensino superior privada sob a ótica da taxonomia de Bloom digital. 2013. Dissertação (Mestrado em Administração) - Universidade Federal de Pernambuco, Recife, 2013.

MORAES, R.; GALIAZZI, M. C. Análise textual discursiva. Ijuí: Unijuí, 2007.

PAIVA, R. A. Webquest: uma coreografia didática para a produção do conhecimento na educação à distância. 2011. 158 f. Dissertação (Mestrado em Educação Matemática e Tecnológica) Universidade Federal de Pernambuco, Recife, 2011.

PAIVA, R. A.; PADILHA, M. A. S. A Webquest e a taxonomia digital de Bloom como uma nova coreografia didática para a educação online. Revista Brasileira de Ensino de Ciências e Tecnologia, Curitiba, v. 5, n. 1, p. 81-100, 2012.

PALFREY, J.; GASSER, U. Nascidos na era digital: entendendo a primeira geração de nativos digitais. Porto alegre: Artmed, 2011.

ROCHA, L. R. A concepção de pesquisa no cotidiano escolar: possibilidades de utilização da metodologia webquest na educação pela pesquisa. 2007. Dissertação (Mestrado em Educação) Universidade Federal do Paraná, Curitiba, 2007.

SANTOS, E. O. A metodologia da webquest interativa na educação online. In: FREIRE, W. (org.). Tecnologia e educação: as mídias na prática docente. 2. ed. Rio de Janeiro: Wak, 2011. p. 107-128.

TEIXEIRA, B. S. et al. Taxonomia de Bloom como instrumento da prática avaliativa na educação. In: ENCONTRO NACIONAL DE PESQUISA EM EDUCAÇÃO EM CIÊNCIAS, 9., 2013, Águas de Lindóia. Atas [...] Águas de Lindóia: ABRAPEC, 2013. 